\title{
A PROdUÇÃo CIENTÍfica NACIONAL EM PERIÓdicos SOBRE O ENSINO DE TERMODINÂMICA
}

\author{
THE NATIONAL SCIENTIFIC PRODUCTION IN JOURNALS ON THE TEACHING \\ OF THERMODYNAMICS
}

DOI: http://dx.doi.org/10.23926/RPD.2526-2149.2019.v4.n2.p559-577.id432

\author{
Geilson Rodrigues da \\ Silva \\ Mestre em Ensino de \\ Ciências (UFMS) \\ Professor da Escola Estadual \\ Viriato Bandeira \\ geilsonrodrigues367@gmail. \\ $\underline{\text { com }}$
}

\section{Nádia Cristina Guimarães Errobidart Doutora em Educação (UFMS) \\ Professora do Instituto de Física (UFMS) \\ nacriguer@gmail.com}

Resumo: Os conceitos que estruturam a Termodinâmica, tais como, calor, temperatura, energia interna, trabalho e entropia são difíceis de serem abordados pois os estudantes de diferentes níveis educacionais possuem concepções espontâneas relacionadas a esses conceitos. Sendo assim, diante das dificuldades advindas das concepções espontâneas, consideramos mapear as pesquisas relacionadas ao Ensino da Termodinâmica, para elucidar quais estratégias vem sendo abordado para o ensino desse conteúdo. Para isso consideramos os artigos publicados em periódicos nacionais com o extrato qualis no Ensino de Ciências entre A1 e B2. Ao todo obteve-se 26 artigos, que abordavam o Ensino de Termodinâmica. Realizou-se o agrupamento em quatro categorias que foram oriundos da análise de crônica sendo: (1) História da Ciência no Ensino da Termodinâmica. (2) O papel da experimentação no Ensino de Termodinâmica. (3) Investigações de conceitos espontâneos e científicos da Termodinâmica e suas implicações para o Ensino de Ciências (4) Materiais didáticos para o Ensino de Termodinâmica. Das pesquisas analisadas o perfil conceitual foi o único articulador teórico que permite abordar às concepções espontâneas e científicas do calor, além disso as diferentes teorias construtivas não foram exploradas de forma ampla nas pesquisas acerca do Ensino da Termodinâmica.

Palavras-chave: Levantamento Bibliográfico; História da Ciência; História do Calor.

\begin{abstract}
The concepts that structure thermodynamics, such as heat, temperature, internal energy, work and entropy are difficult to be addressed because students of different educational levels have spontaneous conceptions related to these Concepts. Thus, given the difficulties arising from the spontaneous conceptions, we consider mapping the researches related to the teaching of thermodynamics, to clarify which strategies have been approached for the teaching of this content. For this we consider the articles published in national journals with the Qualis extract in the teaching of sciences between A1 and B2. In all, 26 articles were obtained, which addressed the teaching of thermodynamics. The grouping was performed in four categories that originated from the analysis of the Chronicle, being: (1) History of Science in the teaching of thermodynamics. (2) The role of experimentation in the teaching of thermodynamics. (3) Investigations of spontaneous and scientific concepts of thermodynamics and their implications for the teaching of Sciences (4) didactic materials for the teaching of thermodynamics. From the researches analyzed, the conceptual profile was the only theoretical articulator that allows addressing the spontaneous and scientific conceptions of heat, besides the different constructive theories were not widely explored in the researches about the teaching of Thermodynamics.
\end{abstract}

Keywords: Bibliographic Survey; History of Science; History of the Heat. 


\section{INTRODUÇÃO}

Segundo Silva, Laburú e Nardi (2008) o estudo do calor é um dos conceitos mais abstratos e rebuscados para se ensinar e apreender. Esses autores dissertaram que além do calor, os demais conceitos da Termodinâmica como a temperatura, energia interna, trabalho e entropia, são difíceis de serem trabalhados, sendo comum se identificarem concepções espontâneas, em estudantes do Ensino Médio até mesmo em estudantes da pós-graduação stricto sensu.

Nesse sentido, Mortimer e Amaral (1998), investigaram a presença de concepções espontâneas, nos estudantes do Ensino Médio, no estudo do calor, pois estes apresentam ideias prévias advindas da forma como utilizamos o conceito de calor nos fenômenos do cotidiano. Sendo que esses autores obtiveram as seguintes concepções espontâneas (1998, p.3): “O calor como substância, há existência de tipos de calor o quente e o frio, além do calor ser diretamente proporcional à temperatura ". No Ensino Superior, Meltzer (2004), identificou o calor como sendo equivalente à quantidade de energia presente nos corpos, assim como que o aumento do trabalho demanda uma diminuição do calor.

Sendo assim, diante das dificuldades advindas das concepções espontâneas que permeiam as concepções dos estudantes dos diversos níveis de ensino, o presente estudo teve como objetivo identificar as pesquisas publicadas em periódicos nacionais com o estrato na área de Ensino de Ciências para elucidar quais estratégias vem sendo abordadas para o Ensino da Termodinâmica.

\section{Metodologia}

O presente estudo trata-se de uma pesquisa bibliográfica, que de acordo com Cervo, Silva e Bervian (2007), permite elucidar a situação de uma área de estudo, a partir de publicações disponibilizadas em artigos, livros, dissertações e teses, sendo possível compreender as contribuições de diferentes vertentes teórico-metodológicos sobre uma temática específica.

Diante dessas especificidades, consideramos como material de análise os artigos publicados em periódicos, que passam por avaliações rigorosas para aceitação pelos pares. Para isso, buscamos na plataforma sucupira a indicação de periódicos com estrato qualis entre A1 e B2, referente ao quadriênio 2013-2016, nacionais com disponibilidade online e gratuita escritos em língua portuguesa. Com relação às pesquisas nas revistas selecionou-se o seguinte conjunto de palavras-chave: Ensino da Termodinâmica, História da Ciência e História do Calor. 
Utilizamos os dispositivos de busca dos periódicos, no qual as palavras chave foram pesquisadas nos títulos, nos resumos dos artigos e por fim no corpo do texto, utilizando o intervalo de tempo de 2003-2017 para englobar uma quantidade maior de artigos. Do montante de artigos obtidos realizou-se uma leitura flutuante com objetivo de selecionar para análise apenas os artigos que convergiam em suas propostas para o Ensino da Termodinâmica.

Para análise dos artigos obtidos no levantamento bibliográfico foi adotada uma análise do tipo crônica conforme proposto por Rosa (2015), que visa produzir uma visão sistêmica acerca de um assunto. Desta forma, a seguir, são apresentados os artigos selecionados para leitura analítica obtidos no levantamento bibliográfico para constituir uma visão mais ampla do campo de pesquisa relacionado ao Ensino da Termodinâmica.

\section{Resultados E DiscuSSÃo}

Utilizando do recorte temporal apresentado e das palavras-chave, obtiveram-se ao todo 189 artigos. Desse total, 26 artigos abordavam o Ensino de Termodinâmica, enquanto os demais trabalhos apresentavam discussões do Ensino de Ciências com outros enfoques e foram excluídos da análise. Desse modo, para expor os resultados obtidos no levantamento é apresentado no quadro 1, uma apresentação geral, com as respectivas palavras chave utilizados na obtenção dos artigos.

Quadro 1 - Periódicos nacionais analisados com qualis A1 e A2

\begin{tabular}{|c|c|c|}
\hline Título do trabalho & Artigo & Palavras Chave \\
\hline $\begin{array}{l}\text { Ciência \& Educação Qualis } \\
\mathrm{A}_{1}\end{array}$ & $\begin{array}{l}\text { A entropia no Ensino Médio: Utilizando } \\
\text { concepções prévias dos estudantes e } \\
\text { aspectos da evolução do conceito. }\end{array}$ & História da Ciência. \\
\hline $\begin{array}{l}\text { Ensaio Pesquisa e Educação } \\
\text { em Ciências- Qualis } A_{1}\end{array}$ & $\begin{array}{l}\text { A História da Ciência no ensino da } \\
\text { Termodinâmica: um outro olhar sobre o } \\
\text { ensino de Física. }\end{array}$ & História da Ciência. \\
\hline $\begin{array}{l}\text { Revista Brasileira de Ensino } \\
\text { de Física- Qualis } A_{1}\end{array}$ & $\begin{array}{l}\text { Os experimentos de Joule e a primeira lei } \\
\text { da termodinâmica. }\end{array}$ & $\begin{array}{l}\text { Ensino da Termodinâmica, } \\
\text { História da Ciência. }\end{array}$ \\
\hline $\begin{array}{l}\text { Revista Brasileira de Ensino } \\
\text { de Física- Qualis } A_{1}\end{array}$ & $\begin{array}{l}\text { A teoria analítica do calor de Joseph } \\
\text { Fourier: uma análise das bases conceituais } \\
\text { e epistemológicas. }\end{array}$ & História da Ciência. \\
\hline $\begin{array}{l}\text { Alexandria Revista de } \\
\text { Educação em Ciências e } \\
\text { Tecnologia } \mathrm{A}_{2}\end{array}$ & $\begin{array}{l}\text { Ensino de Ciências e CTS: Contribuições } \\
\text { ao Aperfeiçoamento } \\
\text { de Situações de Aprendizagem sobre } \\
\text { Entropia e Degradação de Energia. }\end{array}$ & Ensino da Termodinâmica. \\
\hline $\begin{array}{l}\text { Alexandria Revista de } \\
\text { Educação em Ciências e } \\
\text { Tecnologia } \mathrm{A}_{2}\end{array}$ & $\begin{array}{l}\text { Os Livros Didáticos de Física e Suas } \\
\text { Omissões e Distorções na História } \\
\text { do Desenvolvimento da Termodinâmica. }\end{array}$ & Ensino da Termodinâmica. \\
\hline $\begin{array}{l}\text { Caderno Brasileiro de Ensino } \\
\text { de Física- Qualis } \mathrm{A}_{2}\end{array}$ & A Ascenção e a queda da teoria do calórico. & $\begin{array}{l}\text { História do Calor, História da } \\
\text { Ciência. }\end{array}$ \\
\hline $\begin{array}{l}\text { Caderno Brasileiro de Ensino } \\
\text { de Física- Qualis } A_{2}\end{array}$ & $\begin{array}{l}\text { O Entendimento Dos Estudantes Sobre } \\
\text { Energia No Início Do Ensino Médio. }\end{array}$ & Ensino da Termodinâmica. \\
\hline
\end{tabular}




\begin{tabular}{|l|l|l|}
\hline $\begin{array}{l}\text { Caderno Brasileiro de Ensino } \\
\text { de Física } \mathrm{A}_{2}\end{array}$ & $\begin{array}{l}\text { A história da evolução do conceito físico } \\
\text { de energia como subsídio para o seu } \\
\text { ensino e aprendizagem- parte I. }\end{array}$ & História da Ciência. \\
\hline $\begin{array}{l}\text { Caderno Brasileiro de Ensino } \\
\text { de Física } \mathrm{A}_{2}\end{array}$ & $\begin{array}{l}\text { A história da evolução do conceito físico } \\
\text { de energia como subsídio para o seu } \\
\text { ensino e aprendizagem- parte II. }\end{array}$ & História da Ciência. \\
\hline $\begin{array}{l}\text { Caderno Brasileiro de Ensino } \\
\text { de Física } \mathrm{A}_{2}\end{array}$ & $\begin{array}{l}\text { Concepções sobre a natureza do calor em } \\
\text { diferentes contextos históricos. }\end{array}$ & $\begin{array}{l}\text { Ensino da Termodinâmica, } \\
\text { História do Calor, História da } \\
\text { Ciência. }\end{array}$ \\
\hline $\begin{array}{l}\text { Caderno Brasileiro de Ensino } \\
\text { de Física } \mathrm{A}_{2}\end{array}$ & $\begin{array}{l}\text { Reflexões para subsidiar discussões sobre } \\
\text { o conceito de calor na sala de aula. }\end{array}$ & Ensino de Termodinâmica. \\
\hline $\begin{array}{l}\text { Caderno Brasileiro de Ensino } \\
\text { de Física } \mathrm{A}_{2}\end{array}$ & $\begin{array}{l}\text { Proposta de Atividade para a abordagem } \\
\text { do conceito de Entropia. }\end{array}$ & Ensino da Termodinâmica. \\
\hline $\begin{array}{l}\text { Investigações em Ensino de } \\
\text { Ciências } \mathrm{A}_{2}\end{array}$ & $\begin{array}{l}\text { A produção técnico-científica de James } \\
\text { Prescott Joule: Uma leitura a partir da } \\
\text { epistemologia de Ludwick Fleck. }\end{array}$ & $\begin{array}{l}\text { História do Calor, História da } \\
\text { Ciência. }\end{array}$ \\
\hline $\begin{array}{l}\text { Investigações em Ensino de } \\
\text { Ciências A }\end{array}$ & $\begin{array}{l}\text { Análise Histórica do conceito de calor nos } \\
\text { trabalhos de Joule e implicações para o } \\
\text { Ensino de Física. }\end{array}$ & $\begin{array}{l}\text { História do Calor, História da } \\
\text { Ciência. }\end{array}$ \\
\hline
\end{tabular}

Fonte: Dados da pesquisa.

Da mesma forma foram catalogados os trabalhos com os qualis B1 e B2 no quadro a seguir.

Quadro 2 - Periódicos nacionais analisados com qualis B1 e B2

\begin{tabular}{|c|c|c|}
\hline Revista & Artigo & Palavras Chave \\
\hline $\begin{array}{l}\text { Experiências no Ensino de } \\
\text { Ciências } B_{1}\end{array}$ & $\begin{array}{l}\text { Escrita como ferramenta indicativa das } \\
\text { possíveis contribuições de uma atividade } \\
\text { investigativa sobre temperatura para a } \\
\text { aprendizagem. }\end{array}$ & História da Ciência. \\
\hline $\begin{array}{l}\text { Experiências no Ensino de } \\
\text { Ciências } B_{1}\end{array}$ & $\begin{array}{l}\text { Investigando na formação de professores de } \\
\text { Ciências do Ensino Fundamental: Uma } \\
\text { experiência em Física Térmica. }\end{array}$ & Ensino da Termodinâmica. \\
\hline $\begin{array}{l}\text { Experiências no Ensino de } \\
\text { Ciências } B_{1}\end{array}$ & $\begin{array}{l}\text { Calor, Temperatura, Poções e Magia: O uso } \\
\text { do RPG como ferramenta avaliativa em aulas } \\
\text { de Física no Ensino Médio. }\end{array}$ & Ensino da Termodinâmica. \\
\hline Química Nova na Escola $B_{1}$ & $\begin{array}{l}\text { Zonas do Perfil Conceitual de calor que } \\
\text { emergem na fala de professores de Química. }\end{array}$ & História do Calor. \\
\hline Química Nova na Escola $B_{1}$ & $\begin{array}{l}\text { Representações sociais de calor por } \\
\text { estudantes de graduação em Química. }\end{array}$ & $\begin{array}{l}\text { História do Calor, Ensino da } \\
\text { Termodinâmica. }\end{array}$ \\
\hline Química Nova na Escola B 1 & A energia e a Química. & $\begin{array}{l}\text { Ensino da Termodinâmica, } \\
\text { História do Calor. }\end{array}$ \\
\hline Química Nova na Escola B 1 & $\begin{array}{l}\text { Processos endotérmicos e exotérmicos: Uma } \\
\text { visão atômico-molecular. }\end{array}$ & Ensino da Termodinâmica. \\
\hline Química Nova na Escola $B_{1}$ & $\begin{array}{l}\text { Por que não estudar entalpia no Ensino } \\
\text { Médio. }\end{array}$ & Ensino da Termodinâmica. \\
\hline Química Nova na Escola $B_{1}$ & $\begin{array}{l}\text { Quanto mais quente melhor calor e } \\
\text { temperatura no Ensino de Termoquímica. }\end{array}$ & $\begin{array}{l}\text { Ensino da Termodinâmica, } \\
\text { História do Calor. }\end{array}$ \\
\hline $\begin{array}{l}\text { Actio: Docência em Ciências } \\
\mathrm{B}_{2}\end{array}$ & $\begin{array}{l}\text { A construção de um aplicativo interativo } \\
\text { como recurso didático para conceitos } \\
\text { termodinâmicos. }\end{array}$ & Ensino da Termodinâmica. \\
\hline Física na Escola $\mathrm{B}_{2}$ & $\begin{array}{l}\text { Entrevista com o Conde Rumford: Da teoria } \\
\text { do calórico ao calor como uma forma de } \\
\text { movimento. }\end{array}$ & $\begin{array}{l}\text { História da Ciência, História } \\
\text { do Calor. }\end{array}$ \\
\hline
\end{tabular}

Fonte: Dados da pesquisa. 
Buscando agrupar os artigos em temáticas similares, elaboraram-se quatro categorias dispostas a seguir: (1) História da Ciência no Ensino da Termodinâmica, sendo que essa categoria possui duas subcategorias (a) Levantamento histórico de elementos conceituais da Termodinâmica. (b) Aplicações da História da Termodinâmica no Ensino de Física. (2) O papel da experimentação no Ensino de Termodinâmica. (3) Investigações de conceitos espontâneos e científicos da Termodinâmica e suas implicações para o Ensino de Ciências. (4) Materiais didáticos para o Ensino de Termodinâmica. A seguir é apresentada a análise dos trabalhos obtidos.

\subsection{História da CiênCIA no EnSINo da TermodinâMica}

Devido às diferentes vertentes utilizadas pelos autores, essa categoria apresenta duas subdivisões sendo que a primeira utiliza o levantamento histórico e a segunda aponta as aplicações dos elementos históricos da Termodinâmica no Ensino de Física.

\subsubsection{LeVANTAMENTO Histórico DE Elementos CONCEITUAIS DA TERMODINÂMICA}

A pesquisa de Gomes (2015) representa o levantamento histórico de cunho linear que trata de uma descrição de fatos e datas dispostos em uma linha do tempo distante dos aspectos sociais envolvidos na produção do conhecimento científico. Diante disso, o autor analisou a evolução do conceito de energia dividindo seu estudo em parte 1 e 2 listando a evolução do conceito de energia, ao investigar as contribuições de Thomas Young, Johann Bernolli, Galileu Galilei, René Descartes, Gottfried Leibniz, James Joule e William Thomson. Apesar de elucidar uma linha do tempo extensa acerca da evolução do conceito de energia, esse autor não apontou claramente a influência que os fatores sociais e culturais tiveram na elaboração do conceito de energia. Cabendo apenas uma apresentação da evolução das concepções de energia ao longo da História da Ciência, sendo que para o autor o levantamento histórico é importante para demonstrar como foi construído esse conceito.

Já Pifer e Aurani (2015), investigaram a formulação da teoria analítica do Calor na concepção de Joseph Fourier, partindo do estudo da condução de calor em metais, sendo analisada a troca de calor nas seções da barra. Deste modo, Fourier deduziu um conjunto de equações que se tornaram ineficientes quando aplicado no estudo do calor específico e na densidade dos materiais. Apesar dessa ineficiência, Fourier, em estudos posteriores, analisou o fluxo de calor na entrada e na saída dos metais, permitindo então a obtenção de equações matemáticas corretas para interpretar o fluxo do calor. 
Porém os autores do artigo não fazem menção ao desenvolvimento da calorimetria, que foi essencial para o desenvolvimento do conceito de calor específico. A abordagem predominantemente matemática permeou as pesquisas de Fourier, convergindo na publicação dos seus resultados no livro intitulada "Teoria analítica do calor", no qual utiliza a linguagem matemática para o estudo do calor, garantindo assim sólida base para suas ideias.

Segundo os autores que analisaram o trabalho de Fourier, devemos partir do desenvolvimento histórico para evidenciar a natureza da ciência, e consequentemente refletir no Ensino de Ciências, acerca da concepção de ciência pronta e acabada. Com isso esses autores utilizaram o desenvolvimento histórico de cunho linear, entretanto, esses autores não atentaram para a discussão de outra teoria que vinha sendo discutida na academia, não demonstrando se essa teoria influenciou ou não as ideias de Fourier. Essa teoria que era denominada de calórico foi objeto de um levantamento histórico linear do seu surgimento até a sua queda Gomes (2012).

Gomes (2012), ainda esclareceu que a teoria do calórico foi responsável por dificultar os avanços na compreensão da natureza do calor, pois esta teoria estava alicerçada no princípio filosófico de conservação da matéria, no qual o calor não seria nem destruído e nem criado, permanecendo constante no sistema. Medeiros (2009) contrapõe-se ao fato da teoria do calórico não ter apresentado contribuições para a ciência. Segundo esse autor, as bases da teoria do calórico foram importantes para explicações acerca do calor específico, calor latente, assim como a quantidade de calor, permitindo apresentar grande confiabilidade entre a comunidade científica.

Apesar da importância da teoria do calórico esta não respondia a uma série de experimentos conduzidos por Conde Rumford, que foi um dos primeiros cientistas a obter resultados experimentais que iriam confrontar a teoria do calórico. Sendo que três trabalhos apresentaram uma discussão acerca das observações experimentais desse cientista, o primeiro foi Medeiros, (2009) que apresentou uma breve bibliografia desse cientista, bem como, as discussões acerca das observações que ocorrem durante as perfurações de canhões.

Já Gomes (2012) teve uma abordagem semelhante ao de Silva, Forato e Gomes (2013), no sentido de discorrerem a partir de observações sobre o aquecimento de canhões e a perfuração dos mesmos, Conde Rumford elaborou cinco experimentos que em linhas gerais apontaram que todos os experimentos falhavam em indicar qual o efeito do calor sobre a massa dos corpos.

Apesar disso os resultados obtidos por Rumford, foram inconclusivos para superar a teoria do calórico, que possuía respaldo devido ao sucesso na área da calorimetria. Segundo 
Gomes (2012), a teoria do calórico continuou persistindo e influenciando as ideias de outros cientistas tais como Lazare Carnot, que na sua única obra, dissertou acerca das máquinas térmicas ainda sobre viés da teoria do calórico. Sendo reconhecido apenas postumamente que Carnot, passaria a adotar a vertente mecânica para o calor em seus manuscritos.

Para Queirós, Nardi e Delizoicov (2014), a teoria do calórico ainda exerceu predomínio sobre o pensamento de James Joule durante a sua fase técnica que estava imerso na cidade Manchester, cidade com intensa atividade industrial. Os autores apresentaram os fatores sociais e culturais que permearam o desenvolvimento das ideias de Joule, como exemplo, a cervejaria da família de Joule que necessitava de máquinas térmicas cada vez mais eficientes para otimizar os lucros. Isso levou Joule a se interessar pelo estudo da natureza do calor, por necessidade do empreendimento comercial da família, além de manter o interesse pela eletricidade que estava sendo investigada intensamente, visando obter lucros com a sua exploração, pois o governo inglês incentivava os estudos da eletricidade.

Carvalho e Gomes (2017), por sua vez realizaram um estudo do calor a partir das obras originais de Joule em dois momentos distintos da carreira deste cientista, sendo que no primeiro período de seu trabalho as ideias ainda estavam no campo do calórico. E a partir de pesquisas na engenharia, ao tentar ampliar os rendimentos de motores magneto-elétricos, começou a suscitar em Joule dúvidas acerca da real natureza do calor, contribuindo assim para investigações mais estruturadas de cunho científico.

A superação da teoria do calórico foi longa e teve resistência para aceitação dos resultados experimentais que apontavam para a teoria mecânica do calor. Mesmo entre os cientistas que contribuíram para a elucidação da teoria mecânica do calor, as ideias da teoria do calórico, ainda persistiam. Sendo assim, evidenciamos nos trabalhos de Passos (2009), Queirós, Nardi e Delizoicov (2014), Gomes (2015) e Carvalho e Gomes (2017), uma discussão sobre as bases experimentais que levaram Joule a formular o conceito de equivalente mecânico para o calor, que viria romper com a teoria do calórico, ou seja, eles realizaram uma discussão sobre o calor sendo gerado a partir da passagem de corrente elétrica.

Assim sendo, as quatro pesquisas apresentadas acima pontuam nos seus textos a importância desses experimentos para o trabalho de Joule. Além disso, Queirós, Nardi e Delizoicov (2014) e Carvalho e Gomes (2017), pontuaram que é possível recriar experimentos originais, para permitir que os estudantes reflitam e elaborem as suas próprias conclusões, que muitas vezes se assemelham ás concepções dos cientistas que estudaram os experimentos inicialmente. Outro ponto, em que é possível estabelecer paralelos, é em relação à 
epistemologia, que foi abordada no trabalho de Carvalho e Gomes (2017), que apontou a possibilidade de trabalhar elementos da epistemologia de Kuhn no contexto histórico dos trabalhos de Joule. Já Queirós, Nardi e Delizoicov (2014), utilizaram da epistemologia de Fleck mais especificamente o estilo de pensamento, o coletivo de pensamento, a circulação intercoletiva de ideias e práticas e as conexões ativas e passivas para propiciar discussões acerca da mudança do estilo de pensamento de Joule, que passou do técnico para o científico, permitindo assim, a formulação do equivalente mecânico do calor.

Diante das discussões relativas à teoria do calórico é perceptível que essa teoria foi por muito tempo utilizada para elucidar a natureza do calor. E mesmo essa teoria tendo sido superada quanto às explicações acerca da natureza do calor, as seguintes pesquisas identificam a presença do calórico nos livros didáticos para o Ensino Médio: O trabalho de Gomes (2012) alertou também em relação à presença da teoria do calórico nos livros didáticos de Física para o Ensino Médio. Nesse artigo o autor apontou que os docentes devem ter cuidados com a utilização dos livros didáticos, que podem propiciar a formação de concepções incorretas nos discentes do Ensino Médio.

Baldow e Monteiro-Júnior (2010) realizaram um levantamento histórico em fontes secundárias (livros de Física do Ensino Superior e de História) para pavimentar a sua análise nos livros didáticos do Ensino Médio. Porém, essa análise difere inicialmente do trabalho de Gomes, (2012); Silva, Forato e Gomes (2013); e Gomes (2015), ao apresentar, não apenas fatos históricos dispostos de forma linear, agregando os fatores sociais para elucidar o desenvolvimento da Termodinâmica, tais como, a questão da aproximação dos industriais com a academia, com o objetivo de obter lucros com a exploração das patentes. Baldow e MonteiroJúnior (2010), ressaltaram ainda que o desenvolvimento da Termodinâmica teve a contribuição de diversos cientistas, sendo que a tradição de pesquisa inglesa, influenciou o avanço experimental.

Essa tradição de pesquisa recebeu influência de Francis Bacon, enquanto a tradição de pesquisa francesa era teórica, devido à influência de René Descartes. Essas duas tradições de pesquisa se complementavam e foram importantes para desvelar a natureza do calor, sendo que a discussão desses aportes não é encontrada nos demais trabalhos apresentados na presente subcategoria. Entretanto, Baldow e Monteiro-Júnior (2010) apresentaram vários cientistas que contribuíram para o desenvolvimento da Termodinâmica, voltando para a abordagem linear, dissociada do meio social e cultural. 
Após apresentar a discussão histórica do calor, Baldow e Monteiro-Júnior (2010), analisaram cinco livros, que são, segundo os autores, os mais utilizados nas escolas brasileiras. Para isso, eles utilizaram vinte e sete categorias, que foram analisadas nos livros em relação à sua presença ou omissão. Na maior parte das categorias, evidenciaram a omissão dos fatos históricos, assim como, os autores destacaram a ausência da análise sócio-político-econômica, nos livros didáticos.

Além disso, os autores alertam para o fato de os livros didáticos reforçarem uma visão distorcida da ciência, ao apresentarem que a teoria do calórico não teve nenhuma contribuição para o estudo do calor. Da análise dos livros didáticos, os autores apontaram que é possível articular a aproximação disciplinar entre a Física e a História, para a abordagem da Termodinâmica.

A visão utilizada por Silva, Laburú e Nardi (2008) para refletir acerca do ensino do conceito de calor em aulas para o Ensino Médio é linear, sendo que esses pesquisadores apontaram que o ensino do calor apresenta dificuldades conceituais, quando abordados nas aulas, como exemplo, o calor, ser associado à energia. Esses autores analisaram a história do calor a partir de obras secundárias mais especificamente em livros didáticos do Ensino Superior e demonstraram congruência com os demais trabalhos apresentados nessa subcategoria ao dissertar de forma linear sobre a teoria do calórico e o princípio da conservação de energia.

O caminho trilhado por Oliveira e Santos (1998) apresenta o levantamento histórico centrado no estudo da natureza do calor, assumindo como marco os trabalhos de Francis Bacon acerca do calor e apresentando uma evolução linear do conceito de calor até a Termodinâmica estatística de Ludwig Boltzmann. Contudo, a pesquisa não apresenta reflexões acerca da abordagem histórica e suas possíveis contribuições para o Ensino de Ciências, limitando-se apenas a citar brevemente a epistemologia de Bachelard, não apresentando também as suas inferências, acerca dessa vertente epistemológica.

Assim sendo, as discussões apresentadas nessa subcategoria apresentaram os aspectos históricos do calor e dos conceitos que subjazem para a compreensão desta teoria, entretanto os aspectos sociais e culturais são apresentados apenas na pesquisa de Queirós, Nardi e Delizoicov (2014) e de forma incompleta em Baldow e Monteiro-Júnior (2010). Enquanto nas demais pesquisas ocorrem uma discussão centrada no levantamento histórico linear, não discutindo os fatores sociais e culturais. 


\subsubsection{AplicaÇões da História da Termodinâmica no EnSino de Física}

O trabalho de Hülsendeger (2007) defendeu abordagem da História da Ciência no Ensino de Física devido à existência de uma visão estática e acumulativa da Ciência especificamente a Física. Para superar essa visão da Ciência, a autora elaborou uma unidade de aprendizagem utilizando os aspectos históricos referente ao desenvolvimento da Termodinâmica, aliando para isso os conhecimentos de Física, História e Redação que auxiliou os estudantes no desenvolvimento da pesquisa escrita.

A autora realizou uma aproximação disciplinar, maior com a História, no qual foram ministradas aulas nessa disciplina, ressaltando o contexto da mudança política e social e uma nova visão de mundo desde o fim da idade média até o advento da idade moderna, para então situar as causas da primeira revolução industrial, tais como o acúmulo de metais preciosos, advindos da exploração mercantil. Porém a contribuição da autora é muito limitada nos aspectos que elucidam o desenvolvimento das leis da Termodinâmica, tais como a discussão coletiva nos centros acadêmicos da Europa, que só eram acessíveis a uma pequena parcela da população que possuía melhores condições financeiras. Diante disso, o contexto histórico e social, intencionado no estudo conduzido pela autora, não foi contemplado com profundidade.

Covolan e Silva (2005) realizaram uma abordagem pedagógica para o ensino de entropia ao realizaram um pré-teste e um pós-teste. Enquanto atividade pedagógica foi composta por cinco aulas, no qual a primeira aula os autores aplicaram um questionário investigativo para explorar a irreversibilidade, a segunda aula consistiu de uma discussão em grupo com o intuito dos pesquisadores provocarem incoerências nas explicações dos discentes. A terceira e quarta aula foram dedicadas a leitura e discussão do texto "Processos Irreversíveis, Leis da Termodinâmica e Entropia”. E a última aula ocorreu com a resolução de seis questões que avaliaram a evolução conceitual dos estudantes.

A análise dos dados desses autores foi pautada em três categorias para o pré-teste sendo respectivamente: respostas incoerentes, respostas com indicativos de respostas corretas e respostas mais elaboradas. No pós-teste utilizaram-se as mesmas três categorias e emergiu uma quarta categoria que representava as concepções científicas do conceito de entropia. O pré-teste desvelou as concepções espontâneas dos estudantes, alicerçados na percepção dos sentidos, que não é a melhor maneira para estipularmos explicações a respeito da Termodinâmica. Dessa forma, os pesquisadores evidenciaram que os estudantes ainda apresentavam confusões conceituais acerca dos processos espontâneos e da irreversibilidade. Já o pós-teste mostrou-se mais efetivo no sentido da construção de respostas mais elaboradas que apresentam indícios da 
formulação de concepções corretas, ao associar o aumento da desordem do sistema com a entropia.

Sendo assim, todas as pesquisas apresentadas nessa subcategoria, apontaram que a História da Ciência é uma estratégia que pode ser utilizada para superar os métodos tradicionais de ensino que são comumente utilizados para abordagem da Termodinâmica no Ensino Médio.

\subsection{O PAPEL DA EXPERIMENTAÇÃO NO ENSINO DE TERMOdINÂMICA}

Mortimer e Amaral (1998) elaboram quatro atividades simples para explicitar as concepções informais dos estudantes de forma a propiciar a tomada de consciência da existência de dois eixos: os conceitos espontâneos e científicos e saber diferenciá-los. Essa proposta foi pautada na discussão acerca das ideias espontâneas dos estudantes em relação ao calor, pois esses pesquisadores apontaram que a literatura em Ensino de Ciências apresenta o calor como sendo uma substância, além da existência de duas formas de calor o quente e o frio, e o emprego do calor como proporcional à temperatura.

Esses autores utilizaram de conceitos da Termodinâmica, mas com um enfoque no Ensino de Química mais especificamente na Termoquímica. Sendo apresentadas quatro atividades que são respectivamente: A comparação entre o termômetro de laboratório e o clínico, que visa elucidar o princípio zero da Termodinâmica. Na segunda atividade, os autores buscam propor que a sensação de quente e frio nem sempre irá corresponder à diferença de temperatura. Essa atividade apresenta percepções semelhantes à atividade de Pereira, Soares e Andrade (2011) com a experiência envolvendo as sensações térmicas. A terceira atividade preza pela relação entre a diferença de temperatura, por meio da utilização de quantidades iguais de água em distintas temperaturas.

A última atividade propõe a utilização do seguinte esquema experimental: Becker, Água, Suporte, Tubo de Ensaio, para estipular as diferenças entre o calor do ponto de vista científico, que são distintas das noções cotidianas. Os autores discorreram que a utilização dessas atividades permite que os estudantes enriqueçam a sua compreensão conceitual acerca do calor, favorecendo assim a utilização correta dos conceitos científicos, especificamente relacionados ao calor de reação e lei de Hess.

Pereira, Soares e Andrade (2011), realizaram análise da construção conceitual de temperatura pelos estudantes do $1^{\circ}$ Ano do Ensino do Médio do CEFET/RJ, no decorrer de duas aulas de 50 minutos cada. Eles utilizaram atividades investigativas experimentais que permitiram que os discentes formulassem hipóteses, refletissem e argumentassem em grupo. 
Esses autores abordaram a investigação experimental por meio da utilização do sentido do tato a partir de uma experiência com três vasilhas contendo água, sendo dispostas respectivamente em: gelada, temperatura ambiente e morna.

Marques e Araújo (2010), empregaram a alfabetização científica em uma turma de Normal Médio e de Pedagogia, por meio de experimentos acerca da Física Térmica, mais especificamente os tópicos de energia, temperatura, dilatação térmica, calor, transmissão de energia na forma de calor e mudança de fase. Esses autores utilizaram dos aportes da teoria de David Ausubel para estruturar a sequência de atividades, porém não há uma maior discussão, em como a teoria da aprendizagem significativa foi utilizada na sequência. Sendo que esses pesquisadores identificaram, a partir do relato dos participantes, avanços de cunho qualitativo das respostas das questões, principalmente no que tange aos conceitos do ponto de vista científico de calor e temperatura, utilizando os aportes da interpretação cinético-molecular.

Monteiro et al, (2009), realizam uma investigação diferente das apresentadas, ao propor uma atividade experimental centrada na segunda lei da termodinâmica a partir da entropia com a utilização de um experimento que pode ser utilizado em aulas de Física para o Ensino Médio. Esse experimento foi elaborado com o objetivo de reproduzir em nível macroscópico os comportamentos das partículas, entretanto como esse experimento não foi aplicado com estudantes não é possível estabelecer até que ponto essa atividade propicia a aprendizagem.

A preocupação pelo desenvolvimento de atividades experimentais com materiais alternativos permeou as sequências de atividades de todos os trabalhos apresentados nessa categoria. Portanto, percebe-se que o cerne das discussões em todos os trabalhos visava a partir de várias óticas estabelecer diferenças entre as concepções espontâneas e científicas por meio do emprego de atividades experimentais.

\subsection{Investigações de Conceitos Espontâneos E Científicos da TERModinâMiCA}

\section{E SUAS IMPLICAÇÕES PARA O ENSINO DE CIÊNCIAS}

Tratando-se especificamente da entalpia, Silva (2005) dissertou sobre a origem histórica dos conceitos norteadores de entalpia a partir da teoria do calórico até a formulação da Termodinâmica, que permitiu o estabelecimento das variáveis do sistema. Sendo que, para o autor, a dedução matemática da entalpia depende da temperatura, da pressão, bem como, da composição do sistema, que remete à teoria do calórico. Apesar de não apresentar uma intervenção didática com estudantes, esse autor refletiu do ponto de vista teórico acerca das dificuldades dos discentes em compreenderem a entalpia, devido à necessidade de um 
formalismo matemático rebuscado a partir da utilização do cálculo diferencial e integral, tornando-se assim inviável o ensino de entalpia no Ensino Médio.

Os trabalhos de Barros (2009), Diniz-Júnior, Silva e Amaral (2015) e Castro e Ferreira (2015), optaram por trilhar caminhos distintos de uma abordagem histórica centralizada em uma evolução linear dos conceitos relacionados ao calor. O primeiro autor buscou apresentar uma abordagem conceitual sem uma preocupação histórica do calor. Esse autor busca o embasamento científico em autores de livros didáticos para o Ensino Superior de FísicoQuímica, para investigar a partir de uma visão atômico-molecular os processos endotérmicos exotérmicos. Essa abordagem de Barros (2009) difere dos aportes utilizados nas pesquisas de Diniz-Júnior, Silva e Amaral (2015) e Castro e Ferreira (2015), que debruçaram em uma investigação embasada em teóricos da educação em ciências. Mais especificamente no perfil conceitual de Mortimer que representa diferentes formas de pensar um determinado conceito, sendo assim, o alvo de investigações de Diniz-Júnior, Silva e Amaral (2015), centrou-se na análise da fala de professores de Química acerca dos conceitos do calor.

Por sua vez, Castro e Ferreira (2015) utilizaram os aportes da teoria das representações sociais de Moscovici, aliada às noções de obstáculos epistemológicos de Bachelard. Deste modo, ambos trabalhos convergem em uma intervenção qualitativa sendo que Diniz-Júnior, Silva e Amaral (2015), analisaram o discurso de dois professores de química de escolas estaduais de Serra Talhada no (PE), a partir da aplicação de questionário, observação das aulas e com a utilização de uma entrevista semiestruturada. Por outro lado, Castro e Oliveira (2015) utilizaram a técnica de associação livre de palavras para analisar as concepções de estudantes do primeiro e do último semestre do curso de licenciatura e bacharelado em química de uma instituição do ensino superior de Teresina (PI).

Castro e Ferreira (2015) e Diniz-Júnior, Silva e Amaral (2015), utilizam os aportes teóricos dos conceitos de calor, entretanto, por apresentarem uma análise do processo de intervenção didática, a discussão passa a centrar-se em como os estudantes e professores empregam os conceitos de calor em diversas situações, influenciados pelo caráter ontológico das respostas. Dessa forma os trabalhos apresentam diferentes visões, especialmente Castro e Ferreira (2015), que elencaram os elementos temperatura e quente como os principais estruturantes da fala dos estudantes. Esses fatores são derivados dos saberes do cotidiano que se relacionaram na fala dos estudantes e levam a dificuldades de aprendizagem dos mesmos, devido à presença dos obstáculos substancialista e verbalista. 
Apesar de trabalhar com um grupo diferente Diniz-Júnior, Silva e Amaral (2015), identificaram no discurso dos professores a emergência de quatro zonas do perfil conceitual (realista, substancialista, empirista e racionalista), sendo que os professores navegam nessas zonas sem se aterem à explicação conceitual correta durante as aulas. Essas discussões são congruentes ao apontarem que docentes e estudantes mesmo do nível superior apresentam visões distorcidas acerca da natureza do calor.

Essa visão de preocupação com a aprendizagem dos estudantes está em consonância com as ideias de Oliveira e Santos (1998) e de Barros (2009), que dissertaram teoricamente acerca dos conceitos científicos envolvidos no estudo do calor. Sendo que para os primeiros autores a energia é elucidada a partir do princípio de conservação de energia, no qual esses autores apontam incongruências em relação a esse conceito, por exemplo, na conversão de energia química em outras formas de energia, levando aos aspectos polissêmicos do conceito de energia, devido a sua utilização na Física, Química e Biologia.

Os pesquisadores Barbosa e Borges (2006), desenvolveram uma sequência didática para o ensino de energia, no primeiro ano do ensino médio de uma escola pública. Sendo que os autores utilizaram uma estratégia didática pautada no modelamento para que os estudantes modifiquem seus conceitos de energia. E essa modificação dos modelos dos estudantes, vem ao encontro do movimento de mudança conceitual, que preza pela substituição das concepções advindas do cotidiano pelas científicas, essa discussão em torno da mudança conceitual não foi identificada nos demais estudos enquadrados nessa categoria. Esses autores realizaram um préteste com trinta e cinco alunos, consistindo na disposição de 21 figuras que indicavam situações comuns de emprego da energia. Os resultados do pré-teste indicam que os estudantes empregam o conceito de energia associado aos seus conhecimentos do cotidiano. Essa pesquisa evidenciou que durante a sequência didática, os modelos dos estudantes não foram modificados e indicaram ainda que os estudantes têm dificuldade na utilização correta do conceito de energia e também demonstraram concepções espontâneas advindas dos conhecimentos do cotidiano, ao expressarem os seus entendimentos acerca das formas de energia.

Os trabalhos que analisaram a natureza do calor, não apresentaram uma tentativa de superar as concepções espontâneas e nem apresentaram possibilidades de coexistência das concepções espontâneas e científicas. No trabalho de Barbosa e Borges (2016), não houve mudança nos modelos de energia, utilizados pelos estudantes, sendo que as concepções espontâneas ainda são preponderantes nos saberes dos estudantes. Sendo assim, nas pesquisas apresentadas nessa categoria, é necessário um aprofundamento no que tange uma proposta de 
estruturação das concepções espontâneas em consonância com as concepções científicas em uma situação problematizada que permita aos indivíduos refletirem acerca do poder explicativo de cada conhecimento.

\section{Materiais Didáticos PaRa o EnSINO de TERMOdinâMica}

Essa categoria discute as potencialidades do uso de materiais didáticos para o ensino de conceitos da Termodinâmica. Sendo assim, o trabalho de Rothberg e Quinato (2016) objetivou realizar modificações no caderno do estudante e do professor de Física em relação aos temas de entropia e degradação de energia, utilizados pela secretaria estadual de educação de São Paulo. Os autores utilizaram os aportes do movimento CTS (Ciência-Tecnologia e Sociedade), para se aprofundar nas discussões relativas à produção e eficiência da energia, relacionando-as com usinas hidroelétricas. Para isso os autores realizaram inserções no caderno do aluno, com a formulação de novas questões para o processo de transformação de energia, seguidos da inclusão de conteúdo, relacionado à matriz energética mundial.

A pesquisa de Rothberg e Quinato (2016) adaptaram o material didático já existente, enquanto no trabalho de Ramos et al (2017) elaboram um material didático em formato de simulação similar aos softwares disponibilizados na plataforma PhET-Colorado. Por sua vez, Souza e Silva (2014) optam por utilizar um jogo em formato RPG como recurso interativo para o processo de avaliação, sendo que a construção do mesmo não foi apresentada no trabalho, cabendo apenas a exposição das regras do jogo. $\mathrm{O}$ jogo foi aplicado em uma turma de física do $2^{\circ}$ ano do Ensino Médio no decorrer de 2 aulas para explorar os conceitos de transferência de calor, temperatura, escalas termométricas, equilíbrio térmico, capacidade térmica, calor específico e quantidade de calor. A aplicação do jogo permitiu que os estudantes evidenciassem as suas limitações na compreensão dos temas, bem como refletissem, com o auxílio do docente, a forma correta de resolução dos problemas apontados na atividade, propiciando assim a aprendizagem dos conceitos. A simulação desenvolvida por Ramos et al (2017) apresentou conceitos que representam a Termodinâmica tais como a entalpia, entropia, processos endotérmicos, exotérmicos, noções de sistema fechado e adiabático e a interpretação estatística da solvatação. Essa animação não foi aplicada em turmas para verificar o potencial de aprendizado do programa desenvolvido, ficando limitado a uma discussão teórica com a literatura de objetos de aprendizagem.

Os trabalhos apresentados nessa categoria adaptaram e elaboraram materiais didáticos para o ensino de elementos da Termodinâmica, bem como, os aspectos da calorimetria. Porém 
não evidenciamos pesquisas que desenvolveram materiais didáticos, aliados aos fatores sociais e culturais que permearam o desenvolvimento da Termodinâmica.

\section{CONSIDERAÇÕES FINAIS}

A partir da revisão da literatura, elucidaram-se diversas estratégias que foram empregadas para o Ensino da Termodinâmica, tais como, a utilização do levantamento histórico que vem sendo apresentado majoritariamente, como uma descrição de fatos, datas e de grandes nomes da ciência, que são apresentados desvinculados do contexto social e cultural, não evidenciando assim uma visão global do processo de produção do conhecimento científico.

Essa discussão é apresentada de forma conclusiva apenas na pesquisa de Queirós, Nardi e Delizoicov (2014), entretanto esses autores restringiram seus estudos nas contribuições de Joule, para determinação do equivalente mecânico do calor. Deste modo, a História da Ciência é uma das vertentes adotadas nas pesquisas, porém os estudos que utilizaram essa vertente, não aprofundaram os fatores sociais, econômicos e culturais, limitando-se a apresentar os conceitos da Termodinâmica, sem discuti-los com profundidade. Dentre as vertentes elucidadas, que foram utilizadas para o Ensino da Termodinâmica, a experimentação mostrou-se importante para articular os conhecimentos do cotidiano que estruturam as concepções espontâneas acerca do calor com os conhecimentos científicos, demonstrando assim que a primeira forma de conhecimento possui limitações acerca de explicações dos fenômenos da natureza.

Apesar disso, foi evidente que as concepções espontâneas ainda permeiam o discurso dos estudantes e mesmo entre professores. Sendo assim, as pesquisas apresentadas na categoria 3 foram restritas ao evidenciar a influência das concepções espontâneas em diversos conceitos que estruturam a Termodinâmica. Além disso, elucidou-se que as concepções espontâneas, não são facilmente substituídas pelas científicas, evidenciando apenas nas pesquisas de DinizJúnior, Silva e Amaral (2015); Castro e Ferreira (2015) a abordagem de forma articulada entre as concepções espontâneas e científicas e suas relações conceituais que são aplicadas em diferentes contextos. O perfil conceitual elaborado por Mortimer mostrou que ele foi o único articulador teórico citado nas pesquisas com uma estratégia didática que permite abordar as concepções espontâneas e científicas do calor, permitindo assim que os estudantes utilizem de forma correta o conceito de calor em zonas conceituais distintas.

Entretanto, não foram evidenciadas nas pesquisas tentativas de mapear zonas de perfil conceitual para os demais conceitos da Termodinâmica, ficando delimitados ao estudo do calor. 
Além disso, as diferentes teorias construtivas, ainda não foram exploradas de forma ampla nas pesquisas acerca do Ensino da Termodinâmica.

\section{REFERÊNCIAS}

BALDOW, Rodrigo; MONTEIRO-JÚNIOR, Francisco, Nairon. Os livros didáticos e suas omissões e distorções na História e no desenvolvimento da Termodinâmica. Alexandria Revista de Educação em Ciência e Tecnologia. v.3, n.1, p. 3-19, 2010. Disponível em: https://periodicos.ufsc.br/index.php/alexandria/article/view/38013/29013. Acesso em: 19/06/2017.

BARBOSA, João, Paulino, Valde; BORGES, Antônio, Társio. O entendimento dos estudantes sobre energia no início do Ensino Médio. Caderno Brasileiro de Ensino de Física. v.23, n.2, p. 182-217, 2006. Disponível em:

https://periodicos.ufsc.br/index.php/fisica/article/view/6275/12765. Acesso em: 19/06/2017.

BARROS, Haroldo, Lúcio de Castro. Processos Endotérmicos e Exotérmicos: Uma visão atômica- molecular. Química Nova na Escola. v.31, n.4, Novembro, 2009. Disponível em: http://qnesc.sbq.org.br/online/qnesc31_4/04-CCD-7008.pdf. Acesso em: 20/06/2017.

CARVALHO, Bianca, Cintra de; GOMES, Luciano, Carvalhais. Análise história do conceito de calor nos trabalhos de Joule e Implicações para o Ensino de Física. Investigações em Ensino de Ciências. v. 22, n.3, p. 264- 290, 2017. Disponível em:

https://www.if.ufrgs.br/cref/ojs/index.php/ienci/article/view/733. Acesso em: 20/06/2017.

CASTRO, Pablo, Micael, Araújo; FERREIRA, Luciana, Nobre, Abreu. Representações sociais de calor por estudantes de graduação em Química. Química nova na escola. v. 37. n. especial, p. 26-34, 2015. Disponível em:

http://qnesc.sbq.org.br/online/qnesc37_especial_I/06-AF-98-14.pdf. Acesso em: 20/06/2017.

CERVO, Amado, Lúcio; BERVIAN, Pedro, Alcino. Metodologia Científica. 6 ed. Rio de Janeiro: Pearson, 2007.

COVOLAN, Silvia, Cristina, Teodoro; SILVA, Dirceu da. A entropia no Ensino Médio: Utilizando concepções prévias dos estudantes e aspectos da evolução do conceito. Ciência \& Educação, v.11, n.1, p. 98- 117, 2005. Disponível em: http://www.scielo.br/pdf/ciedu/v11n1/09.pdf. Acesso em: 20/06/2017

DINIZ-JÚNIOR, Antônio Inácio; SILVA, João Roberto Ratis, Tenório, da; AMARAL, Edenia, Maria, Ribeiro. Zonas do perfil conceitual de calor que emergem na fala de professores de Química. Química Nova na Escola. v.37, n. especial 1, p. 55-67, 2015. Disponível em: http://qnesc.sbq.org.br/online/qnesc37_especial_I/09-CP-99-14.pdf. Acesso em: 20/06/2017.

GOMES, Luciano, Carvalhais. A Ascensão e queda da teoria do calórico. Caderno Brasileiro de Ensino de Física. v.29, n.3, p. 1030-1073, 2012. Disponível em: Disponível em: https://periodicos.ufsc.br/index.php/fisica/article/view/2175-7941.2012v29n3p1030/23609. Acesso em: 20/06/2017.

GOMES, Luciano, Carvalhais, A história da evolução do conceito físico de energia como subsídio para o seu ensino e aprendizagem- parte 1. Caderno Brasileiro de Ensino de Física. 
v.32, n.2, p. 407- 441, 2015. Disponível em:

https://periodicos.ufsc.br/index.php/fisica/article/view/2175-7941.2015v32n2p407/29993.

Acesso em: 20/06/2017.

GOMES, Luciano, Carvalhais. A história da evolução do conceito físico de energia como subsídio para o seu ensino e aprendizagem- parte 2. Caderno Brasileiro de Ensino de Física. v.32, n.3, p. 738- 768, 2015. Disponível em:

https://periodicos.ufsc.br/index.php/fisica/article/view/2175- 7941.2015v32n3p738. Acesso em: 20/06/2017.

HÜLSENDEGER, Margarete, Jerusa, Varela, Centeno. A História da Ciência no Ensino da Termodinâmica: um outro olhar sobre o ensino de Física. Ensaio Pesquisa e Educação em Ciências. v. 9, n. 2, p. 222- 237, 2007. Disponível em:

http://www.scielo.br/pdf/epec/v9n2/1983-2117-epec-9-02-00222.pdf. Acesso em: 20/06/2018.

MARQUES, Nelson, Luiz, Reyes; ARAÚJO, Solano, Ives. Investindo na formação de professores de ciências do ensino fundamental: uma experiência em Física Térmica.

Experiências em Ensino de Ciências. v.5, n.3, p. 131-152, 2010. Disponível em: http://if.ufmt.br/eenci/artigos/Artigo_ID128/v5_n3_a2010.pdf. Acesso em: 20/06/2017.

MEDEIROS, Alexandre. Entrevista com o Conde Rumford: da teoria do calórico ao calor como uma forma de movimento. Física na Escola. v. 10, n.1, p. 4-16, 2009. Disponível: http://www.sbfisica.org.br/fne/Vol10/Num1/a02.pdf. Acesso em: 20/06/2017.

MELTZER, David, Eduard. Investigation of students' reasoning regarding heat, work, and the first law of thermodynamics in an introductory calculus-based general physics course.

American Journal of Physics. v. 72, n.11, p. 1432-1446, 2004. Disponível em: https://aapt.scitation.org/doi/pdf/10.1119/1.1789161. Acesso em: 28/08/2017.

MONTEIRO, Marco, Aurélio, Alvarenga; MONTEIRO, Isabel, Cristina, de Castro; GASPAR, A; GERMANO, Edmundo. Proposta de Atividade para abordagem do conceito de entropia. Caderno Brasileiro de Ensino de Física. v.26, n.2, p. 367-378, 2009. Disponível em: https://periodicos.ufsc.br/index.php/fisica/article/view/2175-7941.2009v26n2p367. Acesso em: 20/06/2017.

MORTIMER, Eduardo, Fleury; AMARAL, Luiz, Otávio. Quanto mais quente melhor calor e temperatura no Ensino de Termoquímica. Química nova na escola. n.7, p. 30-34, Maio de 1998. Disponível em: http://qnesc.sbq.org.br/online/qnesc07/aluno.pdf. Acesso em: 20/06/2017.

OLIVEIRA, Renato, José de; SANTOS, Joana, Maria. A energia e a Química. Química Nova na Escola. n. 8, Novembro, p. 19-22, 1998. Disponível em: http://qnesc.sbq.org.br/online/qnesc08/conceito.pdf. Acesso em: 20/06/2017.

PASSOS, Júlio, César. Os experimentos de Joule e a primeira lei da termodinâmica. Revista Brasileira de Ensino de Física, v.31, n.3, p. 3603-1- 3603-8, 2009. Disponível em: http://www.sbfisica.org.br/rbef/pdf/313603.pdf. Acesso em: 20/06/2017.

PERREIRA, Marta, Máximo; SOARES, Virtovani; ANDRADE, Viviane, de Abreu. Escrita como ferramenta indicativa das possíveis contribuições de uma atividade investigativa sobre temperatura para a aprendizagem. Experiências em Ensino de Ciências. v.6, n.3, p. 118-132, 
2011. Disponível em: http://if.ufmt.br/eenci/artigos/Artigo_ID164/v6_n3_a2011.pdf. Acesso em: 20/06/2017.

PIFER, Anderson; AURANI, Katya, Margareth. A teoria analítica do calor de Joseph Fourier: uma análise das bases conceituais e epistemológicas. Revista Brasileira de Ensino de Física. v.37, n.1, p. 1603-1-1603-9, 2015. Disponível em: http://www.scielo.br/pdf/rbef/v37n1/01024744-rbef- 37-01-1603.pdf. Acesso em: 20/06/2017.

QUEIRÓS, Wellington, Pereira, de; NARDI, Roberto; DELIZOICOV, Demétrio. A produção técnico-científica de James Prescott Joule: Uma leitura a partir da epistemologia de Ludwik Fleck. Investigações em Ensino de Ciências. v. 19, n.2, p. 99-116, 2014. Disponível em: https://www.if.ufrgs.br/cref/ojs/index.php/ienci/article/view/98/69. Acesso em: 20/06/2017.

RAMOS, Wesley, Candeu; DEL RIO, Bruno, Rafael; BARRETO, Fernando; SUARTJÚNIOR, José, Bento. A construção de um aplicativo interativo como recurso didático para conceitos termodinâmicos. Actio: Docência em Ciências. v.2, n.1, p. 474-492, 2017. Disponível em: https://periodicos.utfpr.edu.br/actio/article/view/6792/4402. Acesso em: 20/06/2017.

ROSA, Paulo, Ricardo, da Silva. Uma introdução à pesquisa qualitativa em ensino. Campo Grande: Editora UFMS, 2015.

ROTHBERG, Danilo; QUINATO, Gabriel, Augusto, Cação. Ensino de Ciências e CTS: Contribuições ao aperfeiçoamento de situações de aprendizagem sobre Entropia e Degradação de Energia. Alexandria Revista de Educação em Ciência e Tecnologia. v.9, n.1, p. 179206, 2006. Disponível em: https://periodicos.ufsc.br/index.php/alexandria/article/view/19825153.2016v9n1p179/31797. Acesso em: 20/06/2017.

SILVA, Ana, Paula, Bispo; FORATO, Thaís, Cyrino de, Melo. GOMES, José, Leandro de Costa Gomes. Concepções sobre a natureza do calor em diferentes contextos históricos. Caderno Brasileiro de Ensino de Física. v.30, n.3, p. 492-537, 2013. Disponível em: https://periodicos.ufsc.br/index.php/fisica/article/view/2175-7941.2013v30n3p492. Acesso em: 20/06/2017.

SILVA, José, Luiz, de Paula, Barros. Por que não estudar entalpia no Ensino Médio. Química Nova na Escola. n. 22, p. 22-25, 2005. Disponível em: http://qnesc.sbq.org.br/online/qnesc22/a04.pdf. Acesso em: 20/06/2017.

SILVA, Osmar, Henrique, Moura; LABURÚ, Carlos, Eduardo; NARDI, Roberto. Reflexões para subsidiar discussões sobre o conceito de calor na sala de aula. Caderno Brasileiro de Ensino de Física, v.25, n.3, p.383- 396, 2008. Disponível em:

https://periodicos.ufsc.br/index.php/fisica/article/view/2175- 7941.2008v25n3p383/8458. Acesso em: 20/06/2017.

SOUZA, Monique, Anara, Siqueira, de. SILVA, Boniek, Venceslau da Cruz. Calor, Temperatura, Poções e Magia: O uso do RPG como ferramenta avaliativa em aulas de Física do Ensino Médio. Experiências em Ensino de Ciências, v.9, n.1. p. 73-89, 2014. Disponível em: http://if.ufmt.br/eenci/artigos/Artigo_ID234/v9_n1_a2014.pdf. Acesso em: 20/06/2017.

Recebido em: 16 de abril de 2019.

Aprovado em: 23 de outubro de 2019. 